\title{
Endometritis in Infertile Couples: The Role of Hysteroscopy and Bacterial Endotoxin
}

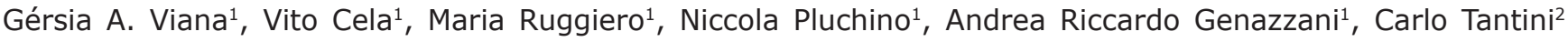 \\ ${ }^{1}$ University of Pisa, Department Reproductive Medicine and Child Development Division of Obstetrics and Gy- \\ necology, Pisa - Italy \\ ${ }^{2}$ University of Siena, Gynecology and Obstetrics Department, Siena - Italy
}

\begin{abstract}
Objective: The role of endometritis on infertility is still controversial. The aim of our prospective controlled study was to select infertile couples and to analyze: hysteroscopic findings of endometritis, bacterial endotoxin level in the menstrual blood, histological pattern of endometrial biopsy and to determine the effect of antibiotic therapy on endometritis resolution.

Methods: 100 infertile couples of University Hospital waiting for in vitro fertilization program. We evaluated the incidence of endometritis in infertile population by hysteroscopy, endometrial biopsy and bacterial endotoxin levels in the menstrual samples. Moreover, we verified the effectiveness of antimicrobial treatment on the endometritis resolution by hysteroscopic control.

Results: Out of 100 women enrolled, 15 showed hysteroscopic evidence of endometritis and 12 of these patients presented higher bacterial endotoxin in the menstrual samples. The histological results were positive for endometritis in 9 cases, 1 woman had no adequate samples and 5 patients had negative result. After antibiotic therapy, 9 patients had a complete hysteroscopic endometritis resolution, 4 patients had an improvement and in 2 cases there was no endometrial change. Concerning histological findings after therapy, we had negative results in 12 patients and persistent inflammatory findings in 2 patients. Conclusion: Our study demonstrated a high incidence of endometritis in infertile couples (15\%). The endometrial biopsy was in agreement with the hysteroscopic findings in $60 \%$ of the cases, and the bacterial endotoxin level in the menstrual samples was higher in 12 patients with suspected endometritis, then its measurement can be helpful to confirm an endometrial infection but its influence must be confirmed with further researches. The antibiotic therapy can improve the hysteroscopic endometrial inflammatory aspect in over $80 \%$ of cases.
\end{abstract}

Keywords: Infertility, endometritis, hysteroscopy, bacterial endotoxin, antibiotic therapy.

\section{INTRODUCTION}

Chronic endometritis (CE) is a subclinical endometrial inflammation. It has been associated with infertility, recurrent abortion, preterm birth and implantation failure in reproductive techniques (Cravello et al., 1997; Devi Wold et al., 2006). Cicinelli et al. (2005a,b; 2008) using fluid hysteroscopy has described diagnostic criteria for chronic endometritis based on the evidence of stromal edema, hyperemia and endometrial micropolyps.

Subclinical inflammation of the endometrium can impair endometrial integrity decreasing the embryo implantation rate in Assisted Reproductive Techniques. In a prospective study, Kamiyama et al. (2004) have demonstrated a negative biological effect of bacterial endotoxin in IVF-ET treatment, suggesting a link between endotoxin levels in menstrual effluent and pregnancy rate. Endotoxins are part of the outer membrane of the cell wall of Gram-negative bacteria. It is a lipopolysaccharide complex associated with the outer membrane of Gram-negative pathogens such as Escherichia coli, Salmonella, Shigella, Pseudomonas, Neisseria, Haemophilus influenza (Todar, 2008).The presence of Endotoxin in IVF culture media has been cited as a potential cause of reduced success in IVF-ET (Romero et al., 2004).

Histologically, CE is characterized by the presence of superficial stromal edema, increased stromal density, and pleomorphic stromal inflammatory infiltrate with predominance of lymphocytes and plasma cells (Sharon et al., 2005).

In a previous study, patients with CE continued to have persistently lower implantation rates despite successful treatment, suggesting a link between CE and infertility (Johnston-MacAnanny et al., 2010). On the other hand, a paper has reported an in vitro fertilization pregnancy in a patient with histologically confirmed chronic endometritis (Fatemi et al., 2009).

The aims of our prospective controlled study were to evaluate in infertile population hysteroscopic findings of endometrial inflammation, endotoxin bacterial level in the menstrual blood and histological pattern of endometrial biopsy. Moreover, we verified the effectiveness of antimicrobial treatment on endometritis resolution by hysteroscopic control.

\section{MATERIAL AND METHODS}

We selected 100 infertile couples at the Reproductive Service of University Hospital of Pisa from January 2010 through December 2011 waiting for in vitro fertilization program. Clinical characteristics of patients enrolled in the study are demonstrated in Table 1 . Exclusion criteria included: echographic suspicion of polyp and myoma, secondary infertility, endometriosis stage III-IV, hydrosalpinx, $\mathrm{FSH}>12 \mathrm{pg} / \mathrm{ml}$ and the use of antibiotics on the month be-

Table 1. Infertile Couples waiting for IVF program

\begin{tabular}{|l|c|}
\hline \multicolumn{1}{|c|}{ Characteristics } & N=100 \\
\hline \multicolumn{1}{|c|}{ Age (years) } & 35.6 (mean) \\
\hline Cause of infertility & \\
Tubal & $44(44 \%)$ \\
Male & $33(33 \%)$ \\
Unexplained & $23(23 \%)$ \\
\hline FSH (3day of the cycle) (mUI/ml) & 8.3 (mean) \\
\hline Previous IVF failure $(\mathrm{n})$ & \\
1 IVF failure before & 27 \\
2 IVF failure before & 27 \\
\hline
\end{tabular}


Table 2. Hysteroscopic findings

\begin{tabular}{|l|c|c|}
\hline Hysteroscopic findings & No. of patients & \% \\
\hline Normal Endometrial aspect & 32 & $32.0 \%$ \\
\hline Endometrial polyps & 15 & $15.0 \%$ \\
\hline Inflammatory Signs of Endometritis: & 7 & \\
\hline Hyperemia & 3 & \\
\hline Hyperemia and Stromal edema & 5 & \\
\hline Hyperemia, Stromal Edema and Micropolyps & & \\
\hline
\end{tabular}

fore the hysteroscopic exam. The study was approved by the Ethics Committee of the University Hospital.

In menstrual phase the patients underwent a menstrual fluid sampling for the measurement of bacterial endotoxin. The access to uterine cavity was transcervically using a plastic catheter Fr.10-sized connected to a $20 \mathrm{~mL}$ plastic syringe in manual aspiration. The menstrual fluids obtained were centrifuged at $3500 \mathrm{rpm}$ for 10 minutes and the fluid part transferred in endotoxin-free containers and frozen at $-20^{\circ} \mathrm{C}$.

The Limulus amebocyte lysate ( $L A L)$ test was used for the detection and quantification of gram negative bacterial endotoxin (Pyrochrome Kit, endpoint method). The endotoxin levels between $0.250 \mathrm{UI} / \mathrm{ml}$ were considered a physiologic response.

The hysteroscopic procedure was performed by three skilled endoscopists using a $2.9 \mathrm{~mm}$ outer diameter (Storz) mini telescope, employing saline distension medium. All patients were in follicular phase. After previous vaginoscopy the uterine cavity exploration was performed, paying special attention on the presence of endometrial inflammatory signs of endometritis. Suspect of CE was based on criteria described by Cicinelli et al. (2005a,b; 2008). After hysteroscopy, endometrial samples were obtained using a vacuum aspiration system (Biogyn) and the material was sent to Anatomic Pathology Laboratory of the University of Pisa for histological examination. A single pathologist studied the endometrial samples.

The patients presenting hysteroscopic findings of endometritis were submitted to empirical antibiotic treatment immediately after the exam using oral doxycycline $200 \mathrm{mg}$ daily for 10 days monthly, repeated after 30 and 60 days associated with vaginal metronidazole. A hysteroscopic follow-up was performed after treatment to verify the effectiveness of antibiotic therapy.

\section{RESULTS}

\section{Hysteroscopic findings}

The hysteroscopic examination of the selected patients identified 15 women (15\%) with endometrial inflammatory signs suggesting endometritis. Three women showed endometrial polyps that were not suspected by echography. We found normal endometrial aspect in 82 exams. The hysteroscopy characteristics are presented on table 2. Hyperemia was verified in 15 patients, 3 of them presented also stromal edema and in 5 cases we found the associa-

Table 3. Bacterial endotoxin measurement and the relationship with suspected endometritis

\begin{tabular}{|c|c|c|}
\hline $\begin{array}{c}\text { Bacterial Endotoxin } \\
\text { Level (UI/mL) }\end{array}$ & $\mathbf{N}$ & $\begin{array}{c}\text { Hysteroscop ic } \\
\text { findings of } \\
\text { Endometritis }\end{array}$ \\
\hline$<0.250$ & 77 & 3 \\
\hline$>0.250$ & 33 & 12 \\
\hline
\end{tabular}

tion of hyperemia, stromal edema and micropolyps.

All the 15 women with suspected endometritis underwent an empirical antibiotic therapy with oral doxycycline and vaginal metronidazole to restore vaginal flora. After antibiotic treatment, hysteroscopic follow-up was performed and demonstrated a complete endometrial inflammatory resolution in 9 patients, an improvement in 4 women and in 2 cases there were not any endometrial modifications.

\section{Bacterial Endotoxin Measurement}

Bacterial Endotoxin was detectable in menstrual effluent of all patients in a range of $0.130 \mathrm{UI} / \mathrm{ml}$ to $0.850 \mathrm{UI} /$ $\mathrm{ml}$. The endotoxin level was $<0.250 \mathrm{UI} / \mathrm{ml}$ in 77 menstrual samples and only three of these patients had presented hysteroscopic findings of endometritis. A high bacterial endotoxin level $(>0.250 \mathrm{UI} / \mathrm{ml})$ was found in 23 women and 12 of them had suspect of endometritis by hysteroscopy (table 3).

\section{Histological Results}

The endometrial biopsies were positive for endometritis in 9 cases, 2 patients presented endometrial polyps and 5 women had no adequate samples for analysis. Negative result was found in 84 patients. Concerning the relationship between hysteroscopic and histological findings of endometritis, 5 patients presenting hysteroscopic suspected endometritis had no histological abnormal findings, moreover, 9 women presenting inflammatory signs of endometritis by hysteroscopy, had a histological confirmation (table 4). For patients submitted to antibiotic treatment, we had negative results in 12 patients and persistent inflammatory findings in 2 patients after therapy.

\section{DISCUSSION}

Currently attention is focused in finding the cause of implantation failure in patients undergoing in vitro fertilization cycles. The host endometrium receptivity is one of the causes that can justify this event.

The role of endometrial sampling for identification and treatment of chronic endometritis (CE) in patients undergoing IVF-ET who repeatedly failed to conceive despite the transfer of good-quality embryos has been studied and the results has demonstrated a lower implantation rates in a subsequent IVF-ET cycle in women with CE on endometrial sampling; however, there were no differences in subsequent clinical pregnancy or ongoing pregnancy rates after successful antibiotic treatment (Johnston-MacAnanny et al., 2010; Biran et al., 2004).

Using the hysteroscopic examination it is possible to evaluate the uterine cavity and to identify endometritis signs that could explain some cases of implantation failure. The histological evaluation can confirm the suspected disease but there is no permanent agreement between hysteroscopic and histological findings. The endometrium samples obtained in initial follicular phase can explain this event, because there is not a lot of material for a diagnose performance (Féghali et al., 2003; Lorusso et al., 2008). 
Table 4. Histological result and relationship with hysteroscopic findings

\begin{tabular}{|l|c|c|}
\hline $\begin{array}{l}\text { Histological } \\
\text { results }\end{array}$ & $\begin{array}{c}\text { No. of } \\
\text { patients }\end{array}$ & $\begin{array}{c}\text { Hys tero s co p i c } \\
\text { aspect of CE }\end{array}$ \\
\hline Negative & 84 & 5 \\
\hline Endometritis & 9 & 9 \\
\hline Polyps & 2 & 0 \\
\hline $\begin{array}{l}\text { No adequate } \\
\text { samples }\end{array}$ & 5 & 1 \\
\hline
\end{tabular}

Concerning antibiotic treatment of subclinical endometritis, prospective randomized studies are needed to verify the benefice on improving pregnancy rates.

The adverse effects of bacterial products in embryo implantation have been studied (Barnhart, 2004; Salim et al., 2002). Detection of bacterial endotoxin in endometrium samples is not a routine in the $\mathrm{Re}$ productive Centers and prospective studies must be performed to confirm the association between endometrium subclinical infection and implantation failure. The potencial effect of endometritis alone on implantation and pregnancy outcome merits further investigations. Maybe in the future it will be possible to predict endometritis by evaluating an endometrium bacterial marker.

\section{CONCLUSION}

The importance of office hysteroscopy in infertile patients is evident, considering the high incidence of subclinical inflammation of the endometrium not detectable by transvaginal sonography. Of the 100 infertile patients selected, 15 women presented suspected endometritis by hysteroscopy. We had a histological confirmation in 9 cases $(60 \%)$ but it's interesting to observe that more than $80 \%$ of them had an improvement of hysteroscopic inflammatory endometrium aspect after antimicrobial treatment.

Bacterial endotoxin is detectable in menstrual blood like it has been demonstrated in previous studies (Kamiyama et al., 2004). Our results demonstrated an endotoxin level of $>0.250 \mathrm{UI} / \mathrm{mL}$ in 12 of 15 patients presenting inflammatory signs of endometritis (80\%), and only three (20\%) women with endometrium inflammatory aspect showed a normal endotoxin level. The significance of high endotoxin level in patients with suspected endometritis must be established, to become a screening method for diagnose of subclinical CE.

Our study suggests an impact of chronic endometritis on infertility but the role of bacterial endotoxin and its management in assisted reproduction should be further investigated in prospective randomized studies as the correlation among hysteroscopic findings, endometrial endotoxin bacterial level and histological exam must be stabilized.

\section{CONFLICT OF INTERESTS}

No conflict of interest have been declared.

\section{Corresponding author:}

Gérsia Araújo Viana

Centro de Medicina Reprodutiva

Av. Adhemar de Barros, 67

Ondina - Salvador, BA - Brazil

E-mail: gersia@hotmail.com

\section{REFERENCES}

Barnhart KT. Microbiology of the endometrium and in vitro fertilization: do we understand the implications? Fertil
Steril.2004;82:797-8.

Biran G, Weissman A, Farhi J, Avinoah I, Shahmorow $M$, Levran $D$ : Is chronic endometritis a causative factor for repeated implantation failure in IVF-ET? Fertil Steril. 2004;82:S128.

Cicinelli E, Resta L, Nicoletti R, Tartagni M, Marinaccio M, Bulletti C, Colafiglio G. Detection of chronic endometritis at fluid hysteroscopy. J Minim Invasive Gynecol. 2005a;12:514-8.

Cicinelli E, Resta L, Nicoletti R, Zappimbulso V, Tartagni M, Saliani N. Endometrial micropolyps at fluid hysteroscopy suggest the existence of chronic endometritis. Hum Reprod 2005b;20:1386-9.

Cicinelli E, De Ziegler D, Nicoletti R, Colafiglio G, Saliani $N$, Resta L, Rizzi D, De Vito D. Chronic endometritis: correlation among hysteroscopic, histologic, and bacteriologic findings in a prospective trial with 2190 consecutive office hysteroscopies. Fertil Steril. 2008; 89:677-84.

Cravello L, Porcu G, D’Ercole C, Roger V, Blanc B. [Identification and treatment of endometritis]. Contracept Fertil Sex.1997;25:585-6.

Devi Wold AS, Pham N, Arici A. Anatomic factors in recurrent pregnancy loss. Semin Reprod Med 2006; 24:25-32.

Fatemi HM, Popovic-Todorovic B, Ameryckx L, Bourgain C, Fauser B, Devroey P. In vitro fertilization pregnancy in a patient with proven chronic endometritis. Fertil Steril. 2009;91:1293.e9-e11.

Féghali J, Bakar J, Mayenga JM, Ségard L, Hamou J, Driguez $\mathrm{P}$, Belaisch-Allart J. [Systematic hysteroscopy prior to in vitro fertilization]. Gynecol Obstet Fertil. 2003;31:127-31.

Johnston-MacAnanny EB, Hartnett J, Engmann LL, Nulsen JC, Sanders MM, Benadiva CA Chronic endometritis is a frequent finding in women with recurrent implantation failure after in vitro fertilization. Fertil Steril. 2010; 93:43741.

Kamiyama S, Teruya Y, Nohara M, Kanazawa K. Impact of detection of bacterial endotoxin in menstrual effluent on the pregnancy rate in in vitro fertilization and embryo transfer. Fertil Steril 2004;82: 788-92.

Lorusso F, Ceci O, Bettocchi S, Lamanna G, Costantino A, Serrati G, Depalo R. Office hysteroscopy in an in vitro fertilization program. Gynecol Endocrinol. 2008;24:465-9.

Romero R, Espinoza J, Mazor M. Can endometrial infection/ inflammation explain implantation failure, spontaneous abortion, and preterm birth after in vitro fertilization? Fertil Steril. 2004;82:799-804.

Salim R, Ben-Shlomo I, Colodner R, Keness Y, Shalev E. Bacterial colonization of the uterine cervix and success rate in assisted reproduction: results of a prospective survey. Hum Reprod. 2002;17:337-40.

Sharon LA, Amortegui AJ, Wiesenfeld HC. Endometrial plasma cells: Do they indicate subclinical pelvic inflammatory disease? Sex Transm Dis 2005; 32(3)185-8.

Todar K. Bacterial Endotoxin. Todar's Online textbook of bacteriology 2008. Available at: www.textbookofbacteriology.net/ 